\title{
The Credit Card and the Crimes Associated with It
}

\author{
Bassam Mustafa Tubishat ${ }^{1} \&$ Khaldoun Fawzi Kandah ${ }^{1}$ \\ ${ }^{1}$ Faculty of Law, Irbid National University, Jordan \\ Correspondence: Bassam Mustafa Tubishat, Faculty of Law, Irbid National University, Jordan. E-mail: \\ dr.bassamtubishat@yahoo.com
}

Received: February 18, 2018

Accepted: March 19, $2018 \quad$ Online Published: April 12, 2018

doi:10.5539/jpl.v11n2p16

URL: https://doi.org/10.5539/jpl.v11n2p16

\begin{abstract}
This study investigates the essence and definition of the credit card. Its types and the correlated crimes that are committed via the credit card such as forging the card, fraud or stealing the card itself. Also, this study investigates the concomitant criminal liability of crimes committed via the credit card.

Moreover, this study concludes that there are no legislative texts dealing with or tackle the crimes of the credit card in the contrastive legislations except in the French one that stated special legislative texts for dealing with such crimes.
\end{abstract}

Keywords: credit card, criminal law, fraud

\section{Introduction}

The use of the computer has spread increasingly in almost all domains of life, especially in the financial institutions like the banks. Therefore, it played a vital and fundamental role in different bank transactions. The emergence of the computer was accompanied by the issuance of credit cards as an alternative of traditional means of financial transactions especially money. Hence, via the use of the credit card which is a plastic card that has a special secret number for its holder, he can withdraw sums of money from ATMs and that card remains the property of its issuer.

\subsection{The Importance of the Study}

The credit card has become one of the commonplaces among people but from the legal perspective its use causes many dilemmas especially within the scope of criminal liability. Its use has increased therefore the concomitant crimes has increased. We can claim that forging such cards, stealing them or using them illegally became the job of some people who try to rob the money of others. the aim of this study is to answer the question whether the legislator has insured protection for using means of electronic payment methods such as the credit card. and if the answer is no, can we consider such means as documents. therefore, applying the traditional texts in penal code concerning the crimes of forging, fraud (The Egyptian legislator names the crime of forging as a crime of fraud whereas the Jordanian legislator used the term forging) or stealing?

\section{The Essence of the Credit Card}

Nowadays, financial institutions and banks depend in their fiscal transactions on the computer and the World Wide Web. and that is achieved by issuing magnetic, plastic cards which enable holders to accomplish a diversity of fiscal transactions such as cash withdraw or payment of purchases

\subsection{Definition of the Credit Card}

Credit cards that are issued by the financial institutions and banks are classified according to the way in which they are used. Either manual cards or automatic processed ones. The manual are not connected with the information system while the automatic processed are connected with the information system. Moreover, the second type may be local that can be used within the same country that issued it or international so it can be used in different countries of the world (Quraha, 2005).

There is no agreed upon definition for the credit card. Some of the literature define it as (the cards that are restricted to be used as a fulfillment tool for purchases or services from accepted merchants to the issuer (Abadeer, 1984).

But in the European legislations, the credit card is defined by the French legislator in the act of cheque security 
and fulfillment cards no 1382/91 in 30/12/1991 states that credit cards are issued by credit institutions or entities mentioned in the eighth article of the act no.46-84 for the year 1984 that regulates credit institutions and activities and enable the holder of the credit card to withdraw or transfer money from his account (Al Khalil, 2005).

The Arabic legislations do not include a definition for the fulfillment or credit cards due to the recency of dealing with such cards. Also, the Arabic legislations lack a legal system that organizes those cards.

Consequently, the credit cards are defined as (plastic cards issued by banking institutions and enable their holders to withdraw or transfer money from their bank accounts).

\subsection{The Components of the Credit Card}

The credit card consists of two entities, one is physical and the other is moral. The physical part is the plastic card itself and a chemical covering in which certain information and data are installed in. The moral component consists of the illegible data and information which are fixed as magnetic tapes on the card. On that tapes certain important details are recorded such as the card number, the national identification a number of its holder and the bank code. the Average human cannot read the previous data except via the computer (Al Fawzan. www.almoslim.net).

And there are other readable data and information scattered on the façade and the back of the card such as the name of the company that issued the card, the account number, the magnetic tape, the signature tape and other information (Al Khalil, 2005).

The secret number does not appear on the credit card and it consists of four digits. through that number the credit card can be used in ATM machines and the holder of the card can be recognized (Hammad, 2009).

\subsection{Types of the Credit Cards}

the credit cards are divided according to their functions into four types: the credit card, the fulfillment card, the check guarantee card and the debit card.

First: The credit card: it is a card that enables its holder to get a credit facility from the bank that issued it. this card permits its owner to use a credit to an agreed extent even if he owes the issuer bank. in this case the bank pays the price of goods or services to the merchant then it recovers what it has paid within agreed upon grace period and of course takes profits (quraha, 2005).

Second: The fulfillment card: this card is considered as a payment tool for the price of goods and services. the holder of this card does not pay in cash but he present the card for merchant who in turn records the information of the card in an invoice of three copies endorsed by the card holder or through recording the secret number. there is a grace period between getting the goods and services and the fulfillment date extends usually from one to six weeks (Kelany, 1995).

Third: The check guarantee card:

Under this card the issuer bank pledges to pay the amounts of checks endorsed by the card holder according to the terms of issuing the card. This card is considered a guarantee for the merchant to get the amount of the check so the card holder must present it along with the check. Then, the merchant records the card information on the back of the check and makes sure of its validity and that the card and the check both hold the same signature, client name and bank name. So, the merchant ensures that he will get the amount of the check from the issuer bank (Salim, 1995).

Fourth: The debit card

This type of cards enables its holder to withdraw cash money from his bank account within agreed upon limit of money via special machines. the client inserts his card in an ATM and he enters the secret number and the required amount of money through a keyboard in the machine then he gets back his card automatically and the taken money is recorded in the client account directly (Al Qudah, 2002).

\section{The Crimes Associated with the Credit Card}

The credit cards are issued by banks or financial institutions to their clients according to a binding contract for two parties.

This card may be exploited to commit illegal conducts whether by its legal holder or others. In this research we will study forms of crimes committed by the legal holder of the card. For example, forging the card, fraud, and stealing the credit card information (Hammad, 2009). 


\subsection{Forging the Credit Card}

Manipulation may take place to the magnetic credit card by forging it. This may happen totally or partially. Total forging takes place when an invalid credit card is fabricated and ascribed to a certain financial institution while the partial forging occur by modifying the credit card information which was originally issued from the financial institution (Al Kalil, 2005).

The crime of forging documents is considered to be one of the most serious crimes that flout the public trust that must exist in formal or conventional documents.

The crime of forging the credit card has some pillars that will be investigated as follows:

First: the supposed pillar is the existence of a document.

The credit card includes normal and magnetic information. The normal information constitutes the ingredients of the document in terms of its material and legal appearance (Abu- Amer, 1987).

In other words, the credit card expresses a group of notions for one person or an entity. So, when it is issued it already has the ingredients of the document and if a falsification takes place to these information that is considered to be forging in a formal or conventional document (salim, 1995).

Concerning the magnetic information and because it is electronically processed on the magnetic tape of the card, when forging occurs, can we consider that to be a case of forging to a document?

The Jordanian legislator has stipulated for the occurrence of a forging crime the existence of an intended falsification to the actions and information in a document and he explained that plainly in the text of the article 260 of the Jordanian penal code number 16 for the year 1960 and its amendments.

That means that the content of the document is visible by the naked eye. Therefore, it does not include the electronic information. Finally, in the light of the principle of legality, it is not acceptable to expand in the explanation of the penal text and that in turn entails the intervention of the legislator to fill that legislative gap.

Second: The material pillar.

The criminal behavior constitutes one of the factors of the material pillar for the forging crime. It consists of two elements, the first is the falsification of the reality, the second is that the falsification must be by one of the forms mentioned in the law exclusively (article 262 of Jordanian penal 1960).

The falsification of the reality in the credit card must affect its essence so that the fixed information is changed. and that can be done through the legally specified falsification means such as manufacturing the card, imitating or endorsing a fake signature on it (Fathallah, 1995).

Third: The moral pillar.

In the case of the offence of forging the credit card, the moral pillar must exist in the form of intention with its two forms. First, the public offense intention which is the knowledge of the criminal of the ingredients of the offense and the trend of his willingness to commit such acts. Second, the special offense intention which is the intention of using the forged card for the purpose of what it has been forged for. That is to say, the criminal intention in the forging offence must be verified at the time of committing the act of forging the card. Therefore, if the criminal intention is verified after the act of forging, then the offense is not realized and in this case it is considered an offense of using a forged card if its conditions are available (Taha,2000).

Fourth: The harm caused by forging.

It is not enough for the realization of the offense of forging the credit card that the reality is changed, but also a harm or a possibility of harm affects the others.

Generally speaking, the harm in the credit card is potential for the individuals or the financial institutions when the forged card is being used. It is worth mentioning that the penal texts differentiated between the act of forging and the act of using and considered them as two separate offenses. Therefore, the offense of forging the credit card is penalized even if not used (Alheensy, 2008).

\subsection{Fraud through the Credit Card}

The jurisprudence defined the act of fraud as deceiving the victim to commit a mistake of submitting his money to the criminal as the basis of using one of the means specified by the criminal legislator (article 417/1 of Jordanian penal 1960). exclusively (AbdelSattar, 1987). Therefore, the offense of fraud requires a special relationship between its parties. In other words, it is not realized without the existence of two processes. First, the act of deceiving and second, receiving the money accordingly. 
And both processes can not be achieved unless there are two persons (AbdelRahman, 1989).

The fraud crime is one of the mental crimes with regards to the victim because the fraud in its essence necessates a human mind that is affected by methods of the criminal. These methods deceive the victim to spend his money inappropriately and without these methods of deception the victim would not have behaved in the same way (Al Khalil, 2005).

So, the fraud crime requires the existence of a human relationship between its two parties, the criminal and the victim. And this relationship does not exist in the case of fraud through the credit card because the relationship here is between a real human being and an ATM machine.

It is known that the ATM is inanimate so the fraud offense is void. Also, for the fraud offense to be realized the submission of money must be willingly by the victim because he was deceived by the methods of the criminal and that condition is not found because the ATM is inanimate therefore not willing (Al Shathely, 2002).

Despite that, the French Court of Cassation has ordained that the fraud offense is realized in the case of the illegal use of the credit card in (ATM machines). And said

It is possible to deceive the ATM machine because is own to someone else (Al Sagheer, 1999).

The judicature asserts the claim that behind every ATM machine there is its owner. Consequently, the relationship between the two parties is humanistic. That is to say, between two persons hence the fraud offense is realized via the use of the credit card.

Also, submitting the money takes place willingly from the side of the victim who is the owner of the machine (the ATM) (Al- Hedaithy, 1996).

And we in turn support the trend of the French Judiciary and claim that the fraud offense is applicable to the credit card at least in the absence of a plain penal text.

\subsection{Stealing the Credit Card}

The article (399) of Jordanian Penal Code no. (16) for the year 1960 defines theft as (taking the property of someone without content)

In this regard, an issue may be raised, are the numbers and the information on the credit card vulnerable to theft? and can they acquire the characteristics of money?

The article (53) of the Jordanian Civil Code no. (34) for the year 1976 defines money as "every concrete or right that has material value in the transaction".

And money includes every thing that can be owned whether material or moral and utilizing it in a legal form and it does not surpass its nature or by the force of law is concerned with the financial rights (Article 54 of Jordanian Civil law 1976).

And for the theft offense via the credit card to take place, it is not enough for the stolen thing to be money, I.e. has the characteristics of money. But also, it must be within the funds included by the criminalization text because for the texts of the theft offense to be applicable it must be concerned with movable assets owned by others (Najem,1995) according to the article (399) of the Jordanian Penal Code and the article (311) of the Egyptian Penal Code (Egyptian penal code no58 1937).

And because the notions, opinions and inventions are not vulnerable to theft unless they are written down on documents or papers so this description applies to the data and information on the magnetic tape of the credit card. Consequently, such data are vulnerable to theft. Hence, we can claim that the theft took place over the data and information that are included on the magnetic tape although the motive behind the theft is the data and information included on such tapes (Hammad, 2009).

\section{The Criminal Liability of the Credit Card Crimes}

The law deems any illegal action a crime that entails a punishment that suits its enormity. Therefore, anyone who commits crimes associated to the credit card bears the criminal liability if its conditions are available. This research will be divided into three sections:

\subsection{The Criminal Liability of the Crimes of Forging the Credit Card}

The Jordanian Penal Code stated the punishment of the crime of forging in the article (265) that people who commit crimes of forging official documents by means mentioned in the previous articles with temporary hard labor or detention in cases when the law does not state otherwise.

And the article (206) of the Egyptian Penal Code states that " anyone who imitated or fabricated one of the 
following things himself or via others will be prosecuted with temporary hard labor or imprisonment " That is to say, both the Jordanian and Egyptian legislators through the abovementioned articles has ordained the punishment of forging the temporary imprisonment or temporary hard labor due to the seriousness of those types of crimes and their adverse consequences on the public interest and are deemed as crimes.

But are the penal texts applicable to the credit card because they penalize the actions of changing the truth and impose suitable punishments at least under the absence of a penal legislative text to shun the legislative gap in the Jordanian law and the necessity of finding penal texts that suits the crimes of the credit card.

But there are some comparative penal legislations that shun the absence of laws that deal with the crimes of the credit card through plain penal texts such as the French legislation. It states that the crime of using the credit card must be separated from the texts of the crime of using a fake document. So, the decree no. 19/88 which tackled the information deception was born and stated the falsification and the use of fake informational documents (Taha, 2000).

The article no (67) of the checks security law and the fulfillment cards no. 1382/491 for the year 1991 states that " anyone of the following will be punished of imprisonment from one to seven years and a fine from 3600 frank to 500000 frank or only one of those punishments:

1) Anyone who imitated or forged the fulfillment or the debit card.

2) Anyone who used or tried to use an imitated or forged fulfillment or debit card and he knew that.

3) Anyone who accepted the payment via the forged fulfillment card although he knew that (Hammad, 2009).

And in this regard, we hope that the Jordanian legislator to overcome legislation lack of the Jordanian Penal Code and to follow the footsteps of the French legislator in order to keep up with the development.

It is worth mentioning that the Jordanian legislator has come up with a special text that tackles the credit cards in the code of electronic crimes but it is not applicable to this subject of this research (article 6 of Jordanian code of electronic crimes no27 2015).

\subsection{The Criminal Liability of the Crimes of Fraud through the Credit Card}

The French Judicature has resorted in resolving the difficulty that it faces in the explanation of the occurrence of the crime of fraud to the legal trick. it supposes that the ATM stands for its owner in the act of money withdrawal. So, the human relationship is available in the crime of fraud when using a forged card.

And in order to tackle this issue, the comparative legislations has followed the footsteps of the French Judicature to avoid such difficulties and to solve the crimes of fraud that take place via the credit card.

Therefore, the article (417) of the Jordanian Penal Code no. (16) for the year 1960 states that " anyone who forces others to submit him movable or immovable funds or a predication including a pledge or a remission of debts and captures them by manipulation will be prosecuted if:

A-" he uses fraudulent methods..."

Also, the article no. (336) of the Egyptian Penal Code states that "anyone who captures the funds, offers, debt securities or bonds will be imprisoned". therefore, they ordained imprisonment as the punishment for the crime of fraud. And according to the supposed pillar in the crime of fraud via the credit card, anyone who commits such acts will be punished with imprisonment with reference to the above mentioned articles.

Eventually, it is necessary to avoid the lack of legislation found in penal legislations to overcome the problems and difficulties that face the adaptation of the crime of fraud via the credit card by creating plain and clear penal texts that deal with these types of crimes such as the comparative legislations like the French one.

\subsection{The Criminal Liability of the Crime of the Credit Card Theft}

Both the Jordanian and the Egyptian legislators, in the articles no. (399-405) of the Jordanian Penal Code and the articles no. (313-327) of the Egyptian Penal Code has stated the punishment of temporary or life imprisonment for any one who commits the crime of theft. Hence, the punishment of theft is applicable to the crimes of the credit cards theft.

So, when the offender steals and uses the credit card, then he will be prosecuted for both the crime of the credit card theft and the crime of fraud as a result of using the stolen credit card.

So, taking the property or extracting it from its owner does not contribute to the real meaning of theft unless accompanied by the intention of possessing and having the appearance of the genuine owner of that property. But the matter differs completely in the case of the credit card because the one who captured the credit card 
without the permission of its owner and used and exploited it to get funds from the account of the victim has taken movable funds owned by the others. Despite the absence of the offender's intention to possess the credit card he still has consumed it and that was emphasized by the French criminal judicature when the French Court of Cassation deemed taking a car with the purpose of using it and then returning it to the place where it was taken from as a theft. So, the conviction of the French Court of Cassation was based on the existence of the intention to own even if temporary (Hammad, 2009).

we can claim that the criminal texts for the crime of theft are not applicable to the crimes of the credit card theft due to the stipulation of the intention to own (special intention) found in both the Jordanian and the Egyptian Penal Codes for such types of crimes. And we in turn appeal the Jordanian Legislator to take into account the necessity of resolving this legislative shortfall and finding clear and plain penal texts dealing with the crimes of the credit card theft especially after the considerable spread of its use in the Jordanian society.

\section{Conclusion}

At the end of this study we come up with the following findings and recommendations such as:

\subsection{The Findings}

1) there is no specific and agreed upon definition that explain the concept of the credit card except in some legislations.

2) The credit card consists of two entities, one is material and the other is moral and it includes a set of legible and illegible data and information that are fixed on magnetic tapes on the card.

3) Credit cards are divided into different types: the debit card, the check security card, the credit card and the fulfillment card.

4) There is a considerable diversity found in the jurisprudence whether the crime of fraud applies to the credit card. One trend claims that such types of crimes are not applicable to the credit card because such crimes require a human relationship between the offender and the victim. This is not available in the crime of fraud via the credit card because the relationship is found between the offender and the computer. Moreover, the crime of fraud requires the existence of the victim's mind that could be deceived but the French Court of Cassation has ordained that the credit card may be vulnerable to the crime of fraud taking into consideration that the computer represents its owner. Hence, the human relationship is achieved.

5) There is lack of specific penal legislations which tackle the crimes of the credit cards in the comparative legislations except in some such as the French legislation.

\subsection{Recommendations}

1) Hopefully, it is of a great importance for the Jordanian legislator to avoid the difficulties and problems facing the credit card by providing special legislations that tackle the illegal use of the credit card so that the offenders could not escape punishment especially after the considerable spread of using such cards.

2) We appeal the Jordanian legislator to follow the footsteps of the French legislator due to the difficulties that face the adaptation of the penal legislations with the credit cards, their nature, and the way of using them.

Moreover, the difficulties caused by misusing the credit card accompanied.

Its early emergence. For example, special gangs were established for the purpose of piracy to exploit the card illegally. For all the previous reasons, it is necessary for the legislator to intervene and come up with plain, direct and legislations to encounter such assaults and to cover the lack in our penal legislation.

\section{References}

Abadeer, R. (1984). The Credit Card from a Legal Point of View. Al-Fatwa and Legislation Management Magazine, (4).

Abdesatar, F. (1987). The Penal Code Explanation. Dar Al- Nahda Al Arabiya, Cairo.

Abelrady, K. (1998). The legal System of the Fulfillment and Guarantee Card. Dar Al-Nahda Al Arabiya, Cairo.

Abu-Amer, M. Z. (1987). The Penal Code. Special Section.

Al- Fawzan, S. M. (n.d.). The Credit Card: Its Definition and imposing fees on it. Retrieved from http://www.almoslim.net

Al Hadethy, F. A. (1999). The Penal Code Explanation. Special Section, Azaman Press, Baghdad. 
Al Khalil, E. A. (2005). The Penal Protection for the fulfillment Cards (1st ed.). Dar Wael for Pubication, Amman.

Al-Khees, A. (2008). The Penal Protection for the Magnetic Credit Cards against Forgery. Damascus University Magazine of Economic and Legal Sciences, (2).

Al-qudah, F. M. (n.d.). The Responsibility of Banks Resulting from Using the Computer as a Means of Fulfillment. A research paper presented to the conference of law and computer, The Faculty of Sharia and Law, The UAE University.

Al-Sagheer, J. A. (1999). The Criminal and Civil Protection for the Magnetic Credit Cards. Dar Al-Nahda Al-Arabiya, Cairo.

Ashathely, F. A. (2002). Assault Crimes against People and Funds. Dar El-Matboat Al-Jamiyah, Alexandria.

Bassala, R. F. (1995). Credit Card Crimes. Dar Ashorouq, Cairo.

Farid, N. A. (2005). The Economic Computer Crimes. Comparative Study, Al-Halaby Publications, Beirut.

Hammad, M. (2009). The Criminal Protection for the Magnetic Credit Cards. Shatat Presses, Ciro.

Najem, M. S. (1996). The Penal Code Explanation. Special Section, Dar Ethaqafah for Publication and Distribution, Amman.

Saleh, N. A. (1995). Lectures on the Penal Code. Public Section, Dar El-fiker for Publication and Distribution, Amman.

Salim, O. (1995). The Criminal Protection for the Fulfillment Card. Comparative Study, Dar-Al Nahda AlArabiya, Cairo.

Sorur, A. F. (1999). The Mediator in the Penal Code. Special Section, Dar Al-Nahda Al-Arabiya, Cairo.

Taha, A. H. (2000). The Crimes Arising from Using the Computer. Dar Al-Nahda Al-Arabiya, Cairo.

The Egyptian Penal Code no ( 58) for the year 1937 and its amendments.

The Jordanian Civil Law no (43) for the year 1976.

The Jordanian Law of Electronic Crimes no ( 27) for the year 2015.

The Jordanian Penal Code no (16) for the year 1960 and its amendments.

\section{Copyrights}

Copyright for this article is retained by the author(s), with first publication rights granted to the journal.

This is an open-access article distributed under the terms and conditions of the Creative Commons Attribution license (http://creativecommons.org/licenses/by/4.0/). 